\title{
RNA helicases in bacteria
}

Vanessa Khemici and Patrick Linder

Department of Microbiology and Molecular Medicine, CMU, Faculty of Medicine, University of Geneva

1, rue Michel Servet, 1211 Geneva 4, Switzerland

patrick.linder@unige.ch

RNA plays a crucial role in the control of bacterial gene expression, either as carrier of information or as positive or negative regulators. Moreover, the machinery to decode the information, the ribosome, is a large ribonucleoprotein complex composed of rRNAs and many proteins. RNAs are normally single stranded but have the propensity to fold into secondary structures or anneal each other. In some instances these interactions are beneficial for the function of the RNA, but in other cases they may be deleterious. All cells have therefore developed proteins that act as chaperones or helicases to keep RNA metabolism alive.

\section{Helicases are grouped into six superfamilies}

RNA helicases form, together with DNA helicases and DNA or RNA translocases, 6 superfamilies (SF) that can readily be distinguished based on their amino acid sequence [1]. Within their conserved core they harbour one or two domains that resemble the recombination protein RecA and are therefore referred to as RecAlike domains. SF1 and SF2 are composed of mono-or oligomeric enzymes and contain DNA helicases and all RNA helicases known so far. Superfamilies 3 to 6 are composed of multimeric, ringforming structures (for review see [1]). With the exception of SF5 that is composed of a single protein, the well characterized termination factor Rho, all other superfamillies 3-6 contain DNA helicases, translocases and AAA+ proteins (ATPases Associated with various Activities). In the following, we will describe what is known about RNA helicases in bacteria. 


\section{Superfamily 1 RNA helicases}

The superfamily 1 is composed of three families of helicases, the UvrD/PcrA/Rep family, the Pif1/RecD family, and the Upf1 family. The UvrD/PcrA/Rep family and the Pif1/RecD family contain DNA helicases that are involved in DNA metabolism in prokaryotes and eukaryotes. The Upf1 family has so far only been described for eukaryotic cells. Upf1 proteins were found in various screens to be implicated in processes that involve DNA or RNA.

\section{Upf1 family}

The Upf1 protein (upf = up frameshift) was originally identified in yeast as a suppressor of frameshift mutations and found to be involved in nonsense mediated RNA decay (NMD) [2]. Upf1 from yeast and human were shown to be efficient 5'-3' ATP dependent RNA helicases and involved in disassembly of RNP complexes in vivo, prior to degradation of the RNA [3]. However Upf1 could also use DNA as a substrate and aside its function in NMD, it was also found to participate in the nucleus in DNA replication as well as telomere maintenance [4]. Thus, it seems that Upf1 has a split personality and possesses different functions.

Analysis of a number of bacteria from different phyla showed that a few encode proteins with various degrees of homology with the core region of yeast Upf1 (amino acids 361 -840) (Figure 1), but to the best of our knowledge, none of these genes has been described in the literature and it remains to be determined whether they function as RNA helicases and/or rather as DNA helicases.

\section{Superfamily 2 RNA helicases}

Superfamily 2 contains several families of RNA helicases (DEAD, DEAH/RhA, Ski2-like, viral DExH), but harbors also DNA helicases (Rad3/XPD, RecQ, RecG) and translocases (type I restriction enzymes; SWI/Snf-like proteins) [5]. The conserved motifs of the superfamily 2 proteins are similar throughout, but sufficiently different to clearly attribute a given protein to one or another family (Figure 1). 


\section{DEAD-box proteins}

DEAD-box RNA helicases represent the largest family of RNA helicases. Although referred to as helicases, they are characterized by a poor helicase activity able to unwind only short RNA or DNA-RNA duplexes and perform local strand separation in a non-processive manner. Elucidation of their mechanism of action was obtained mainly by the structural analysis of the Drosophila DEAD-box RNA helicase Vasa [6]. When bound to a double stranded substrate, the protein induces a kink in the nucleic acid inducing a local strand separation, that can be further used for either protein-binding to one of the strands, or annealing with another nucleic acid, for example a small regulatory RNA. Moreover, analysis of the ATPase activity has shown that only ATP binding is required for unwinding, but ATP hydrolysis is necessary for recycling of the protein [7] and a loading strand is required in some instances, but does not serve as translocation track for the helicase [8]. Such an activity confers a broad variety of activities to DEADbox RNA helicases, which in some cases are not related to RNA unwinding. Indeed, in addition to these strand separation events, DEAD-box proteins were also shown in vitro to displace proteins from RNA [9], to form stable complexes with RNA [10] or to facilitate annealing of two complementary RNAs [11]. Many of the bacterial DEAD-box proteins were found serendipitously in a variety of screens and selections (Table 1) or identified by a targeted search for conserved motifs. Nevertheless in many cases the function of the DEAD-box protein is not clear. Only few bacterial DEAD-box proteins have been studied and their activity is so far restricted to ribosome biogenesis, RNA decay, and translation initiation. In a phylogenetic analysis of the DEAD-box proteins, we found that most bacteria, with few exceptions, encode at least one DEAD-box RNA helicase and some up to 12 different members [12]. The bacterial DEAD-box proteins used in this study clustered into 25 different groups but few of these groups, mainly from E. coli, have been studied so far, which could indicate that new functions or properties of a so far unstudied group may be discovered. In the following section we will describe the processes in which some information on the function of RNA helicases is available. 
One of the best characterized bacterial DEAD-box proteins is RhlB from E. coli. It facilitates the degradation by the exoribonuclease PNPase of RNA intermediates harboring strong secondary structures [13]. The coordination of their activity requires their association with the essential endoribonuclease RNase $E$ that functions as the scaffold of the RNA degradosome and stimulates the activity of RhlB, although a RNase E independent RhlB-PNPase complex was reported in the literature $[14,15]$. RNA degrading complexes associating ribonucleases with helicases appear to be a ubiquitous concept exemplified in eukaryotes by the exosome that also contains an RNA helicase, albeit a Ski2-like protein [16]. In Bacillus subtilis and Staphylococcus aureus the degradosome is composed of a different set of ribonucleases and the DEAD-box protein CshA $[17,18]$. First described in S. aureus as involved in biofilm formation [19], CshA is now known to play a general function in mRNA decay [20]. The decreased biofilm production is the consequence of an inefficient degradation of the agr mRNA in a $\triangle c s h A$ strain (Figure 2a) [21]. However, the structure(s) of the degradosome or its subcomplexes involved in RNA turnover are not known and more importantly neither the molecular signatures of the target RNAs nor the partner(s) that require or regulate the activity of CshA are known.

\section{Ribosome biogenesis}

Hints for a role of DEAD-box proteins in ribosome biogenesis were given since their first description in E. coli. Two of the five DEAD-box proteins in E. coli, SrmB and CsdA (originally named DeaD and subsequently renamed CsdA $[22,23]$, we use the nomenclature CsdA, to avoid confusion with the wrongly annotated DeaD from B. subtilis, that in fact should be YxiN [24]), were originally isolated as multicopy suppressors of temperature sensitive mutations in ribosomal protein genes L24 and S2, respectively [22,25]. Since then, a careful analysis has shown that both SrmB and CsdA are required for $50 \mathrm{~S}$ biogenesis, especially at low temperature in E. coli $[26,27]$. Moreover, an elegant genetic screen from the Dreyfus laboratory identified the sites of action of SrmB to be present in the rRNA, providing new insights onto the molecular function of SrmB (Figure 2b) [28]. Intriguingly, the authors reported that SrmB would not need its ATPase function for this activity. Two other DEAD-box proteins of E. coli, RhlE 
and $\mathrm{DpbA}$ also appear to act in ribosome biogenesis. The latter one represents a unique case as DpbA is specifically activated by a specific part of the 23S RNA [29]. Intriguingly, the deletion of $d p b A$ does not affect ribosome biogenesis, suggesting that its function is either not essential or could be bypassed under the tested conditions. Nevertheless, overexpression of a DbpA with a mutation in motif VI, involved in ATP hydrolysis, leads to growth and ribosome biogenesis defects [30]. Similarly, rhlE deletion does not lead to a growth deficiency, but genetic interactions with $\mathrm{SrmB}$ and CsdA suggested a role in ribosome biogenesis [31]. It is interesting to note that bacteria that have a large number of DEAD-box proteins have several copies that are most closely related to RhlE [12]. Whether these would function in ribosome biogenesis or in other processes is unknown. Studies in B. subtilis or Listeria also suggested that DEAD-proteins function in ribosome biogenesis although a much more in-depth analysis will be required to confirm their function [32,33].

Translation initiation

RNA helicases are known to play important roles for translation initiation in eukaryotes to allow binding and scanning of the small ribosomal subunit. In bacteria, the binding to the ribosome binding sequence (RBS) has been shown to be an important step that can easily be regulated by secondary structures or antisense RNA. Surprisingly few examples were reported in which DEAD-box proteins alter the accessibility of the SD sequence [34-36]. CsdA was shown to be required for the annealing of a small regulatory RNA, DsrA, to the 5' UTR of $r p o S$ to free the RBS sequence [34]. It also has been shown to stimulate the translation of the transcriptional regulator UvrY, which is regulated by an extended putative secondary structure. In this case the CsdA requirement is abolished if mutations are introduced into a stem structure, but re-established if complementary mutations restore the stem-loop structures [36]. In addition to UvrY the authors also identified 38 other RNAs that were enriched in a high throughput sequencing of RNAs cross-linked to a tagged CsdA suggesting a more wide function for CsdA in translational control. A very recent publication shows that CsdA from Pseudomonas is required for the modification of a secondary structure to efficiently express ExsA, a transcription factor of the TTSS (type three 
secretion system). Both, deletion of the 5'UTR or replacement of the beginning of the protein coding sequence of ExsA from heterologous systems, abolish the formation of the secondary structure and the requirement of CsdA (Figure 2c) [35]. In these cases it is not known whether the helicase acts alone and how it is directed to its target. Could this be through an association with the small ribosomal subunit?

\section{DEAH-box proteins}

DEAH-box proteins are highly similar to DEAD-box proteins but show some distinct motifs, such as the DEAH motif, the signature of this family. They have been studied extensively in baker's yeast where they were identified as factors in splicing and ribosome biogenesis. They were reported to perform 3'-5'

unwinding, but can also be involved in protein dissociation from a substrate RNA (e.g., [37]). They are thought to perform biochemical activities that are similar to those of DEAD-box proteins, but DEAH family proteins are promiscuous for the NTP hydrolysis. Like in the case of DEAD-box proteins, DEAH-box proteins are stimulated by accessory proteins. In the case of Prp43, the interaction and stimulation by the G-patch proteins Ntr1 and Pfa1 for ribosome biogenesis and pre-mRNA splicing, respectively, is a beautiful example how accessory proteins can target and regulate RNA helicases in different cellular processes $[37,38]$.Relatively little is known about DEAH-box proteins in bacteria. A phylogenetic tree of bacterial DEAH proteins showed three different groups called HrpA-like, HrpB-like and Z5898-like found exclusively in proteobacteria and actinobacteria [12]. Only HrpA-like and Z5898-like proteins have been studied experimentally. HrpA has been shown to be required for the processing of the daa operon encoding a fimbrial adhesin. The structural gene of fimbria encoded by daaE, which is the last gene of the operon, is needed in greater abundance than the preceding genes. To differentially express these genes, the full length mRNA is cleaved in the penultimate gene, in a translation dependent manner, by a so far unidentified endonuclease. The upstream part of the mRNA is then rapidly degraded, whereas the downstream part, encoding daaE, is stabilized by a 3' hairpin structure. Using a clever GFP sorting system, mutants deficient in the cleavage were enriched and one mutation was found to locate in 
HrpA (Figure 2d) [39]. In another report, deletion of HrpA or mutations affecting the ATPase or helicase activity in Borrelia burgdorferi resulted in loss of infectivity in mice [40]. This study proposed that HprA has global function in gene regulation as indicated by a partial proteome analysis revealing 90 downand 97 up-regulated proteins. The third bacterial DEAH-box protein described in the literature is encoded by a pathogenicity island (called motility associated $\mathrm{O}$ MAO - island) in E. coli 0157:H7, but also present in two unrelated E. coli and two Salmonella strains [41]. Mutation of the Z5898 DEAH-box helicase gene resulted in down regulation of flagellin and reduced motility. Intriguingly, the authors show that fliC expression is down regulated and a GFP fusion indicated that this occurs at the transcriptional level, but further analysis is required to fully understand the role of $\mathrm{Z} 5898$.

\section{$\underline{\text { Ski2-like proteins }}$}

The Ski2-like family is named after a yeast protein originally identified as conferring a super killer phenotype if mutated in a strain containing linear dsRNA virus like particles. In baker's yeast, the family is composed of Ski2 itself, its homologue Mtr4, Brr2, and Slh1 [42]. The structural analysis was very much facilitated by using the archaeal Hel308 DNA helicase [43]. Ski2 and Mtr4 are helicases of the cytoplasmic and nuclear exosome complexes, respectively. Brr2 is involved in pre-mRNA splicing and Slh1 is involved in transcription and translation. Ski2-like proteins are also composed of two RecA domains, with a wedge in the second domain to separate the strands when the helicase translocates with 3'-5' polarity using a putative inchworm mechanism, helped by a ratched domain [44]. An analysis of bacterial genomes reveals that closest homologs of Ski2-like proteins are found mainly in Cyanobacteria and Actinobacteria. HelY from Mycobacterium smegmatis was recently shown to be an RNA-stimulated ATPase and an RNA:RNA or RNA:DNA helicase [45]. Nevertheless, to the best of our knowledge, no bacterial Ski2-like protein has been characterized in vivo so far.

\section{Non-DEAD and non-DEAH RNA unwinding proteins}

In addition to the RNA helicases characterized by the conserved motifs including 
the Walker A (I) and Walker B (II) motifs, there are also a variety of other proteins that modify RNA structures that do not belong to these families. Here we describe two examples, RNase R or CsrA.

RNase R was originally described as vacB virulence factor from Shigella flexneri [46]. It is $60 \%$ homologous to RNase II and deletion of RNase R is synthetically lethal with a PNPase deletion [46], which both have a 3'-5' exonuclease activity. Interestingly RNase R popped up in a suppressor screen for a $\operatorname{cs} d A$ helicase mutant [47]. In contrast to PNPase and other exoribonucleases, RNase R can efficiently degrade structured RNA and has, in addition to its nucleolytic activity, an RNA helicase activity. As a complete surprise, the Deutscher laboratory reported recently the presence of an ATPase motif II at the N-terminus and a motif I at the C-terminus and showed that binding to ATP was required for its helicase activity [48]. The mutational analysis of these motifs showed that they are indeed necessary for ATPase and helicase and affect ribonuclease activity, especially at low temperature.

Another example of an RNA structure modifying protein is CsrA, involved in adaptation to many different environmental changes (for a recent review, see [49]). CsrA is a small peptide that generally binds to a sequence containing a GGA motif, explaining its preference for ribosome binding sequences, and thereby often functioning as a translational repressor. CsrA also binds to the small RNAs CsrB and CsrC, that play an important role in CsrA mediated regulation by titrating this RNA binding protein. Very recently, it has been shown that CsrA can destabilise an RNA secondary structure that normally hides the termination factor Rho binding site rut and thereby allows transcription termination of the pgaABCD operon, involved in extracellular polysaccharide adhesion synthesis [50]. Interestingly, CsdA and SrmB regulate CsrB and CsrC expression by stimulating translation initiation of UvrY (see above), the transcriptional activator of CsrB and CsrC [36].

\section{Conclusion}

Bacterial DEAD-box proteins were discovered in many different screens and in some cases their function in a particular process could be identified. Although their function in these processes fit perfectly with their predicted biochemical 
activity, such as unwinding secondary structures for RNA degradation or rearranging RNP complexes in ribosome biogenesis, in most cases the molecular function has not been defined precisely. With the availability and combination of state of the art techniques such as crosslinking methods, RNA deep sequencing, and sophisticated genetic screens it will be hopefully possible to delineate their molecular functions more precisely.

In general and even if DEAD-box protein are not likely to be redundant, their inactivation does not lead to a severe phenotype under standard laboratory conditions, they are crucial in some growth or stress conditions suggesting a role in more competitive environments. Moreover, some DEAD-box proteins, such as exemplified by CsdA, are likely to be involved in different processes, possibly by interacting with different mediators.

Another remaining and intriguing question is the absence of DEAD-box proteins in some bacteria. This could be explained for bacteria living at elevated temperature or for Chlamydia by their intracellular growth at moderate temperature. But how do Borrelia manage to grow without these proteins at lower temperature? Have they evolved the DEAD-box protein targets in such a manner that these proteins are no longer required, or do they use other proteins? In contrary, do bacteria that have multiple DEAD-box protein genes (up to 12 for Shewanella) use different DEAD-box proteins for different growth conditions? And finally, it is striking that many DEAD-box proteins were identified in genetic screens, but so far Upf1-like and Ski2-like proteins have only been identified by bioinformatics. Future work will be needed to elucidate the molecular functions played by these proteins from different families..

\section{Acknowledgments}

We are very grateful to P. Redder and J. Armitano for comments on the manuscript. Work in the Linder laboratory is supported by the Swiss National Science Foundation and the University of Geneva. We are very grateful for additional support by the Fondation Ernst et Lucie Schmidheiny, Fondation Boninchi, Swisslife, Novartis Jubiläumsstiftung, and the Novartis Consumer Health Foundation. We would like to apologize for the many references that could not be included because of place limitations. 


\section{Figure legends}

Figure 1: Conserved motifs within the different helicase proteins allow them to cluster within families.

Proteins from yeast and humans (top line for each family) are very similar to those from bacteria (bottom line for each family). Red residues were fully conserved amongst the proteins analysed in a given family. For the Upf1 family 13 eukaryotic and 100 bacterial sequences were aligned and residues were given if 8 and 80 or more sequences were identical, respectively. For DEAD box proteins, residues were indicated if 35 or more out 61 eukaryotic sequences and 46 out of 77 bacterial sequences were identical. For DEAH-box proteins residues are indicated if 16 out of 23 and 60 out of 100 or more sequences were identical. For Ski2-like proteins, residues were retained when 6 out of 10 and 80 out of 99 or more sequences were identical, for eukaryotic and bacterial proteins, respectively. For bacterial Ski2-like proteins the similarity was very high, since most of the proteins were from Cyanobacteria or Actinobacteria, and only two sequences from Chloroflexi, one sequence from Fibrobacteres, one sequence from Chlamydiae, and one sequence from Proteobacteria.

\section{Figure 2a: The DEAD-box RNA helicase CshA is involved in RNA degradation.}

A genetic screen for mutants with decreased biofilm formation identified CshA from S. aureus. In absence of CshA, the agr mRNA is stabilized. This leads to increased RNA III levels through activation of the quorum sensing system, composed of AgrB, the transporter, AgrD, the signaling peptide or auto-inducer, AgrC, the sensor, and AgrA, the transcriptional activator of the agr and the RNA III promoters. This regulatory RNA is known to regulate several target genes positively or negatively leading to reduced expression of surface proteins, and increased expression of secreted proteins such as hemolysins.

Figure 2b: SrmB prevents deleterious annealing of $23 S$ and $5 S$ rRNAs. This genetic screen used an E. coli strain in which all 7 rRNA operons were deleted and the only copy was present on a plasmid. This strain also contained a deletion of the $s r m B$ gene, rendering the strain cold sensitive. Screening for mutations that allowed growth a low temperature identified mutations in the $23 \mathrm{~S}$ rRNA or the $5 \mathrm{~S}$ rRNA genes. Interestingly, the mutations were located in repeated sequences that are complementary between the $23 \mathrm{~S}$ and the $5 \mathrm{~S}$ rRNA.

Figure 2c: CsdA/DeaD was identified in a screen for mutations that reduce cytotoxicity of Pseudomonas.

In absence of CsdA the ExsA gene expression is reduced, resulting in delayed cytotoxicity. If the $5^{\prime}$ upstream region or the beginning of the reading frame is exchanged with the sequence from other but related genes the expression becomes CsdA independent .

Figure 2d: The production of sufficient quantities of fimbrial proteins requires a processing event of the daa mRNA.

Under normal conditions, the daa operon is cleaved in a translation dependent 
manner within the daaP gene. A fusion of a GFP reporter gene in its 3 ' region with the daaP containing cleavage sequence and the 3 ' protecting secondary structure will show reduced GFP activity if the transcript is processed [39]. If the processing cannot take place, as for example in absence of HrpA, the 3' situated secondary structure will protect the entire mRNA and increase the GFP expression. 
Table 1: In vivo phenotypes associated with mutants in RNA helicases

\begin{tabular}{|c|c|c|c|}
\hline Protein & In vivo phenotypes & Organism & Reference \\
\hline \multirow[t]{2}{*}{ CrhC } & $\begin{array}{l}\text { Induced if shifted to } 20^{\circ} \mathrm{C} \text {, induction is light } \\
\text { dependent }\end{array}$ & Anabaena sp PCC 7120 & [51] \\
\hline & Membrane associated & Anabaena sp PCC 7120 & [52] \\
\hline \multirow[t]{3}{*}{ CrhR } & Induced by light, not detectable in the dark & Synechocystis sp. PCC 6803 & [53] \\
\hline & Altered morphology and surface & Synechocystis sp. PCC 6803 & [54] \\
\hline & Autoregulation in response to temperature stress & Synechocystis sp. PCC 6803 & [55] \\
\hline \multirow[t]{15}{*}{ CsdA } & Multicopy suppressor of $r p s B^{t s}$ (S2 protein) & E. coli & [22] \\
\hline & Ribosome biogenesis, 50S & E. coli & [26] \\
\hline & Cold shock induced & E. coli & [23] \\
\hline & Cold sensitive & $\begin{array}{l}\text { E. coli, L. pneumophila, } Y \text {. } \\
\text { pseudotuberculosis }\end{array}$ & {$[26,56,57]$} \\
\hline & Synthetic interaction with $r n e^{t s}$ & E. coli & [58] \\
\hline & 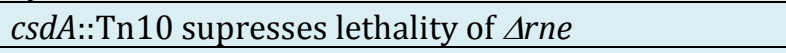 & E. coli & [59] \\
\hline & Assembles with cold induced degradosome & E. coli & [58] \\
\hline & Stabilisation of $\operatorname{csp} A \mathrm{mRNA}$ at $15^{\circ} \mathrm{C}$ in a $\operatorname{csd} A$ mutant & E. coli & [47] \\
\hline & Synthetic enhancement with $\Delta R N a s e R$ & E. coli & [47] \\
\hline & $\begin{array}{l}\text { Cold sensitivity can be partially supressed by } \\
\text { overexpression CspA or RNase R }\end{array}$ & E. coli & [60] \\
\hline & $\begin{array}{l}\text { Overexpression of CsdA permits efficient } \\
\text { translation of CAT reporter }\end{array}$ & E. coli & [61] \\
\hline & Required for TTSS expression & Pseudomonas & [35] \\
\hline & Required for RpoS expression & E. coli & [34] \\
\hline & Stimulates UvrY translation & E. coli & [36] \\
\hline & Stimulates SirA translation & Salmonella & [36] \\
\hline \multirow[t]{11}{*}{ CshA } & Identified in a screen for exported proteins & S. pneumoniae & [62] \\
\hline & Required for aggregation of bacteria & L. reuteri & [63] \\
\hline & Increased resistance to oxidative stress & C. perfringens & [64] \\
\hline & Required for catalase activity & E. faecalis & [65] \\
\hline & Cold shock response & B. subtilis & {$[66,67]$} \\
\hline & Sediments with polysomes & B. subtilis & [68] \\
\hline & Defect in ribosome biogenesis & L. monocytogenes & {$[32,33]$} \\
\hline & Stimulates biofilm formation & S. aureus & [19] \\
\hline & Interaction with degradosome & B. subtilis, S. aureus & {$[17,18,20]$} \\
\hline & Cold sensitive & $\begin{array}{l}\text { B. subtilis, B. cereus, } S \text {. } \\
\text { aureus, L. monocytogenes }\end{array}$ & $\begin{array}{l}{[21,69,70]} \\
{[71]}\end{array}$ \\
\hline & Reduced motility & L. monocytogenes & [71] \\
\hline \multirow[t]{4}{*}{ CshB } & Reduced growth rate & U. parvum & [72] \\
\hline & Cold sensitive & B. cereus, B. subtilis, S. aureus & {$[32,73,74]$} \\
\hline & Upregulation of phenolic acid decarboxylase ( $\mathrm{padA}$ ) & L. plantarum & [75] \\
\hline & $\begin{array}{l}\text { Reduced expression in late exponential and } \\
\text { stationary phase }\end{array}$ & B. subtilis & [17] \\
\hline DbpA & $\begin{array}{l}\text { R331A is dominant negative when overexpressed } \\
\text { in a wild-type background }\end{array}$ & E. coli & [76] \\
\hline \multirow[t]{2}{*}{ RhlB } & Accumulation of degradation intermediates in vivo & E. coli & [13] \\
\hline & Required for axenic growth & B. bacteriovorus & [77] \\
\hline \multirow[t]{5}{*}{ RhlE } & Multicopy suppressor of $\Delta c s d A$ & E. coli & {$[31,47]$} \\
\hline & $\begin{array}{l}\text { Its overexpression exacerbate the cold sensitivity of } \\
\Delta \operatorname{srm} B\end{array}$ & E. coli & [31] \\
\hline & Decreased survival after freezing & C. crescentus & [78] \\
\hline & Upregulated in the cold & P. arcticus $273-4$ & [79] \\
\hline & Reduced pathogenicity in Nematodes & P.luminescens LN2 & [80] \\
\hline \multirow[t]{3}{*}{ SrmB } & Multicopy suppressor of L24 & E. coli & [25] \\
\hline & Cold sensitive & E. coli & [27] \\
\hline & Defect in ribosome biogenesis & E. coli & [27] \\
\hline
\end{tabular}




\section{References:}

1. Singleton MR, Dillingham MS, Wigley DB: Structure and mechanism of helicases and nucleic acid translocases. Ann. Rev. Biochem. 2007, 76:23-50.

2. Leeds P, Peltz SW, Jacobson A, Culbertson MR: The product of the yeast UPF1 gene is required for rapid turnover of mRNAs containing a premature translational termination codon. Genes Dev 1991, 5:23032314.

3. Franks TM, Singh G, Lykke-Andersen J: Upf1 ATPase-dependent mRNP disassembly is required for completion of nonsense- mediated mRNA decay. Cell 2010, 143:938-950.

4. Chawla R, Redon S, Raftopoulou C, Wischnewski H, Gagos S, Azzalin CM: Human UPF1 interacts with TPP1 and telomerase and sustains telomere leading-strand replication. EMBO J 2011, 30:4047-4058.

5. Fairman-Williams ME, Guenther UP, Jankowsky E: SF1 and SF2 helicases: family matters. Curr. Opin. Struct. Biol. 2010, 20:313-324.

* This is the standard work for the classification of SF1 and SF2 proteins into families

6. Sengoku T, Nureki O, Nakamura A, Kobayashi S, Yokoyama S: Structural basis for RNA unwinding by the DEAD-box protein Drosophila Vasa. Cell 2006, 125:287-300.

** The strucutre of vasa suggested that the local and polarity independent strand separation by DEAD-box proteins was due to a kingin the substrate RNA

7. Chen Y, Potratz JP, Tijerina P, Del Campo M, Lambowitz AM, Russell R: DEADbox proteins can completely separate an RNA duplex using a single ATP. Proc Natl Acad Sci U S A 2008, 105:20203-20208.

8. Yang Q, Jankowsky E: The DEAD-box protein Ded1 unwinds RNA duplexes by a mode distinct from translocating helicases. Nat Struct Mol Biol 2006, 13:981-986.

9. Fairman M, Maroney PA, Wang W, Bowers H, Gollnick P, Nilsen TW, Jankowsky E: Protein displacement by DExH/D RNA helicases without duplex unwinding. Science 2004, 304:730-734.

10. Ballut L, Marchadier B, Baguet A, Tomasetto C, Seraphin B, Le Hir H: The exon junction core complex is locked onto RNA by inhibition of eIF4AIII ATPase activity. Nat. Struct. Mol. Biol. 2005, 12:861-869.

11. Chamot D, Colvin KR, Kujat-Choy SL, Owttrim GW: RNA structural rearrangement via unwinding and annealing by the cyanobacterial RNA helicase, CrhR. J Biol Chem 2005, 280:2036-2044.

12. Redder P, Hausmann S, Khemici V, Yasrebi H, Linder P: Bacterial versatility requires DEAD-box RNA helicases. FEMS Microbiol Rev 2015.

13. Khemici V, Carpousis AJ: The RNA degradosome and poly(A) polymerase of Escherichia coli are required in vivo for the degradation of small mRNA decay intermediates containing REP-stabilizers. Mol Microbiol 2004, 51:777-790.

14. Vanzo NF, Li YS, Py B, Blum E, Higgins CF, Raynal LC, Krisch HM, Carpousis AJ: Ribonuclease E organizes the protein interactions in the Escherichia coli RNA degradosome. Genes Dev 1998, 12:2770-2781. 
15. Tseng YT, Chiou NT, Gogiraju R, Lin-Chao S: The Protein Interaction of RNA Helicase B (RhlB) and Polynucleotide Phosphorylase (PNPase) Contributes to the Homeostatic Control of Cysteine in Escherichia coli. J Biol Chem 2015.

16. Makino DL, Schuch B, Stegmann E, Baumgartner M, Basquin C, Conti E: RNA degradation paths in a 12-subunit nuclear exosome complex. Nature 2015, 524:54-58.

17. Lehnik-Habrink M, Pfortner H, Rempeters L, Pietack N, Herzberg C, Stulke J: The RNA degradosome in Bacillus subtilis: identification of CshA as the major RNA helicase in the multiprotein complex. Mol Microbiol 2010, 77:958-971.

<The first description opf a DAEAD-box protein as part of the degradosome form Gram positive bacteria

18. Roux CM, Demuth JP, Dunman PM: Characterization of components of the Staphylococcus aureus messenger RNA degradosome holoenzymelike complex. J Bacteriol 2011.

19. Tu Quoc PH, Genevaux P, Pajunen M, Savilahti H, Georgopoulos C, Schrenzel J, Kelley WL: Isolation and characterization of biofilm formationdefective mutants of Staphylococcus aureus. Infect Immun 2007, 75:1079-1088.

20. Giraud C, Hausmann S, Lemeille S, Prados J, Redder P, Linder P: The Cterminal region of the RNA helicase CshA is required for the interaction with the degradosome and turnover of bulk RNA in the opportunistic pathogen Staphylococcus aureus. RNA Biology 2015, 12:658-674.

21. Oun S, Redder P, Didier JP, Francois P, Corvaglia AR, Buttazzoni E, Giraud C, Girard M, Schrenzel J, Linder P: The CshA DEAD-box RNA helicase is important for quorum sensing control in Staphylococcus aureus. $R N A$ Biol 2013, 10:157-165.

22. Toone WM, Rudd KE, Friesen JD: deaD, a new Escherichia coli gene encoding a presumed ATP-dependent RNA helicase, can suppress a mutation in $r p s B$, the gene encoding ribosomal protein $\mathrm{S} 2$. J. Bacteriology 1991, 173:3291-3302.

23. Jones $P G$, Mitta M, Kim Y, Jiang W, Inouye M: Cold shock induces a major ribosomal-associated protein that unwinds double-stranded RNA in Escherichia coli. Proc. Natl. Acad. Sci. USA 1996, 93:76-80.

24. Kossen K, Uhlenbeck OC: Cloning and biochemical characterization of Bacillus subtilis YxiN, a DEAD protein specifically activated by $23 S$ rRNA: delineation of a novel sub-family of bacterial DEAD proteins. Nucleic Acids Res 1999, 27:3811-3820.

25. Nishi K, Morel-Deville F, Hershey JWB, Leighton T, Schnier J: An eIF-4A-like protein is a suppressor of an Escherichia coli mutant defective in $50 \mathrm{~S}$ ribosomal subunit assembly. Nature 1988, 336:496-498, and correction, Nature 340: 246.

26. Charollais J, Dreyfus M, Iost I: CsdA, a cold-shock RNA helicase from Escherichia coli, is involved in the biogenesis of $50 \mathrm{~S}$ ribosomal subunit. Nucleic Acids Res 2004, 32:2751-2759. 
27. Charollais J, Pflieger D, Vinh J, Dreyfus M, Iost I: The DEAD-box RNA helicase SrmB is involved in the assembly of $50 \mathrm{~S}$ ribosomal subunits in Escherichia coli. Mol Microbiol 2003, 48:1253-1265.

28. Proux F, Dreyfus M, Iost I: Identification of the sites of action of SrmB, a DEAD-box RNA helicase involved in Escherichia coli ribosome assembly. Mol Microbiol 2011, 82:300-311

** In a genetic screen, inverted repats in the $23 \mathrm{~S}$ and $5 \mathrm{~S}$ rRNa were identified as targets of SrmB.

29. Tsu CA, Kossen K, Uhlenbeck OC: The Escherichia coli DEAD protein DbpA recognizes a small RNA hairpin in 23S rRNA. RNA 2001, 7:702-709.

30. Sharpe Elles LM, Sykes MT, Williamson JR, Uhlenbeck OC: A dominant negative mutant of the E. coli RNA helicase DbpA blocks assembly of the 50S ribosomal subunit. Nucleic Acids Res 2009, 37:6503-6514.

31. Jain C: The E. coli RhlE RNA helicase regulates the function of related RNA helicases during ribosome assembly. $R N A$ 2008, 14:381-389.

32. Lehnik-Habrink M, Rempeters L, Kovacs AT, Wrede C, Baierlein C, Krebber H, Kuipers OP, Stulke J: DEAD-Box RNA helicases in Bacillus subtilis have multiple functions and act independently from each other. J Bacteriol 2013, 195:534-544.

33. Netterling S, Vaitkevicius K, Nord S, Johansson J: A Listeria monocytogenes RNA helicase essential for growth and ribosomal maturation at low temperatures uses its $\mathrm{C}$ terminus for appropriate interaction with the ribosome. J Bacteriol 2012, 194:4377-4385.

34. Resch A, Vecerek B, Palavra K, Blasi U: Requirement of the CsdA DEAD-box helicase for low temperature riboregulation of rpoS mRNA. RNA Biol 2010, 7:796-802.

35. Intile PJ, Balzer GJ, Wolfgang MC, Yahr TL: The RNA Helicase DeaD Stimulates ExsA Translation To Promote Expression of the Pseudomonas aeruginosa Type III Secretion System. J Bacteriol 2015, 197:2664-2674.

** A detailed analysis of the 5 ' untranslated region and the beginning of the open reading frame of ExsA showed that CsdA is necessary for efficient translation initiation, most likely by unwinding a secondary strucutre

36. Vakulskas CA, Pannuri A, Cortes-Selva D, Zere TR, Ahmer BM, Babitzke P, Romeo T: Global effects of the DEAD-box RNA helicase DeaD (CsdA) on gene expression over a broad range of temperatures. $\mathrm{Mol}$ Microbiol 2014, 92:945-958.

37. Tanaka N, Aronova A, Schwer B: Ntr1 activates the Prp43 helicase to trigger release of lariat-intron from the spliceosome. Genes Dev. 2007, 21:2312-2325.

38. Lebaron S, Papin C, Capeyrou R, Chen YL, Froment C, Monsarrat B, Caizergues-Ferrer M, Grigoriev M, Henry Y: The ATPase and helicase activities of Prp43p are stimulated by the G-patch protein Pfa1p during yeast ribosome biogenesis. EMBO J. 2009, 28:3908-3819.

39. Koo JT, Choe J, Moseley SL: HrpA, a DEAH-box RNA helicase, is involved in mRNA processing of a fimbrial operon in Escherichia coli. $\mathrm{Mol}$ Microbiol 2004, 52:1813-1826. 
*Using a clever screening method, the authors identified the first bacterial DEAHbox protein function

40. Salman-Dilgimen A, Hardy PO, Dresser AR, Chaconas G: HrpA, a DEAH-box RNA helicase, is involved in global gene regulation in the Lyme disease spirochete. PLoS One 2011, 6:e22168.

41. Xu Y, Xu X, Lan R, Xiong Y, Ye C, Ren Z, Liu L, Zhao A, Wu LF, Xu J: An 0 Island 172 Encoded RNA Helicase Regulates the Motility of Escherichia coli 0157:H7. PLoS One 2013, 8:e64211.

42. Johnson SJ, Jackson RN: Ski2-like RNA helicase structures: common themes and complex assemblies. RNA Biol 2013, 10:33-43.

43. Richards JD, Johnson KA, Liu H, McRobbie AM, McMahon S, Oke M, Carter L, Naismith JH, White MF: Structure of the DNA repair helicase hel308 reveals DNA binding and autoinhibitory domains. J Biol Chem 2008, 283:5118-5126.

44. Taylor LL, Jackson RN, Rexhepaj M, King AK, Lott LK, van Hoof A, Johnson SJ: The Mtr4 ratchet helix and arch domain both function to promote RNA unwinding. Nucleic Acids Res 2014, 42:13861-13872.

45. Uson ML, Ordonez H, Shuman S: Mycobacterium smegmatis HelY Is an RNA-Activated ATPase/dATPase and 3'-to-5' Helicase That Unwinds 3'-Tailed RNA Duplexes and RNA:DNA Hybrids. J Bacteriol 2015, 197:3057-3065.

46. Cheng ZF, Zuo Y, Li Z, Rudd KE, Deutscher MP: The vacB gene required for virulence in Shigella flexneri and Escherichia coli encodes the exoribonuclease RNase R. J Biol Chem 1998, 273:14077-14080.

47. Awano N, Xu C, Ke H, Inoue K, Inouye M, Phadtare S: Complementation analysis of the cold-sensitive phenotype of the Escherichia coli csdA deletion strain. J Bacteriol 2007, 189:5808-5815.

48. Hossain ST, Malhotra A, Deutscher MP: The Helicase Activity of Ribonuclease R is Essential for Efficient Nuclease Activity.J Biol Chem 2015, 290:15697-156706.

* This work identified the Walker A and Walker B motifs in a very unusual constellation and showed that ATP hydroysis per se is not required for unwinding, as it was found for DEAD-box proteins

49. Vakulskas CA, Potts AH, Babitzke P, Ahmer BM, Romeo T: Regulation of bacterial virulence by Csr (Rsm) systems. Microbiol Mol Biol Rev 2015, 79:193-224.

50. Figueroa-Bossi N, Schwartz A, Guillemardet B, D'Heygere F, Bossi L, Boudvillain M: RNA remodeling by bacterial global regulator CsrA promotes Rho-dependent transcription termination. Genes Dev 2014, 28:1239-1251.

51. Chamot D, Owttrim GW: Regulation of cold shock-induced RNA helicase gene expression in the Cyanobacterium anabaena sp. strain PCC 7120. J Bacteriol 2000, 182:1251-1256.

52. El-Fahmawi B, Owttrim GW: Polar-biased localization of the cold stressinduced RNA helicase, CrhC, in the Cyanobacterium Anabaena sp. strain PCC 7120. Mol Microbiol 2003, 50:1439-1448.

53. Kujat SL, Owttrim GW: Redox-regulated RNA helicase expression. Plant Physiol 2000, 124:703-714. 
54. Rosana AR, Ventakesh M, Chamot D, Patterson-Fortin LM, Tarassova O, Espie GS, Owttrim GW: Inactivation of a low temperature-induced RNA helicase in Synechocystis sp. PCC 6803: physiological and morphological consequences. Plant Cell Physiol 2012, 53:646-658.

55. Rosana AR, Chamot D, Owttrim GW: Autoregulation of RNA helicase expression in response to temperature stress in Synechocystis sp. PCC 6803. PLoS One 2012, 7:e48683.

56. Soderberg MA, Cianciotto NP: Mediators of lipid A modification, RNA degradation, and central intermediary metabolism facilitate the growth of Legionella pneumophila at low temperatures. Curr Microbiol 2010, 60:59-65.

57. Palonen E, Lindstrom $M$, Somervuo P, Johansson P, Bjorkroth J, Korkeala H: RNA helicase CsdA is needed for growth of Yersinia pseudotuberculosis IP32953 at low temperature. Appl Environ Microbiol 2011.

58. Prud'homme-Genereux A, Beran RK, Iost I, Ramey CS, Mackie GA, Simons RW: Physical and functional interactions among RNase E, polynucleotide phosphorylase and the cold-shock protein, CsdA: evidence for a 'cold shock degradosome'. Mol Microbiol 2004, 54:1409-1421.

59. Tamura M, Kers JA, Cohen SN: Second-site suppression of RNase E essentiality by mutation of the deaD RNA helicase in Escherichia coli. J Bacteriol 2012, 194:1919-1926.

60. Awano N, Rajagopal V, Arbing M, Patel S, Hunt J, Inouye M, Phadtare S: Escherichia coli RNase $R$ has dual activities, helicase and RNase. J Bacteriol 2010, 192:1344-1352.

61. Butland G, Krogan NJ, Xu J, Yang WH, Aoki H, Li JS, Krogan N, Menendez J, Cagney G, Kiani GC, et al.: Investigating the in vivo activity of the DeaD protein using protein-protein interactions and the translational activity of structured chloramphenicol acetyltransferase mRNAs. J Cell Biochem 2007, 100:642-652.

62. Pearce BJ, Yin YB, Masure HR: Genetic identification of exported proteins in Streptococcus pneumoniae. Mol Microbiol 1993, 9:1037-1050.

63. Roos S, Lindgren S, Jonsson H: Autoaggregation of Lactobacillus reuteri is mediated by a putative DEAD-box helicase. Mol Microbiol 1999, 32:427-436.

64. Briolat V, Reysset G: Identification of the Clostridium perfringens genes involved in the adaptive response to oxidative stress. J Bacteriol 2002, 184:2333-2343.

65. Baureder M, Hederstedt L: Genes important for catalase activity in Enterococcus faecalis. PLoS One 2012, 7:e36725.

66. Hunger K, Beckering CL, Wiegeshoff F, Graumann PL, Marahiel MA: Coldinduced putative DEAD box RNA helicases CshA and CshB are essential for cold adaptation and interact with cold shock protein B in Bacillus subtilis. J Bacteriol 2006, 188:240-248.

67. Beckering CL, Steil L, Weber MH, Volker U, Marahiel MA: Genomewide transcriptional analysis of the cold shock response in Bacillus subtilis. J Bacteriol 2002, 184:6395-6402. 
68. Ando Y, Nakamura K: Bacillus subtilis DEAD protein YdbR possesses ATPase, RNA binding, and RNA unwinding activities. Biosci Biotechnol Biochem 2006, 70:1606-1615.

69. Pandiani F, Brillard J, Bornard I, Michaud C, Chamot S, Nguyen-the C, Broussolle V: Differential involvement of the five RNA helicases in adaptation of Bacillus cereus ATCC 14579 to low growth temperatures. Appl Environ Microbiol 2010, 76:6692-6697.

70. Broussolle V, Pandiani F, Haddad N, Michaud C, Carlin F, Nguyen-the C, Brillard J: Insertional mutagenesis reveals genes involved in Bacillus cereus ATCC 14579 growth at low temperature. FEMS Microbiol Lett 2010, 306:177-183.

71. Markkula A, Mattila M, Lindstrom M, Korkeala $H$ : Genes encoding putative DEAD-box RNA helicases in Listeria monocytogenes EGD-e are needed for growth and motility at 3 degrees C. Environ Microbiol 2012.

72. Aboklaish AF, Dordet-Frisoni E, Citti C, Toleman MA, Glass JI, Spiller OB: Random insertion and gene disruption via transposon mutagenesis of Ureaplasma parvum using a mini-transposon plasmid. Int J Med Microbiol 2014, 304:1218-1225.

73. Redder P, Linder P: New Range of Vectors with a Stringent 5-Fluoroorotic Acid-Based Counterselection System for Generating Mutants by Allelic Replacement in Staphylococcus aureus. Appl Environ Microbiol 2012, 78:3846-3854.

74. Pandiani F, Chamot S, Brillard J, Carlin F, Nguyen-the C, Broussolle V: Role of the five RNA helicases in the adaptive response of Bacillus cereus ATCC 14579 cells to temperature, $\mathrm{pH}$, and oxidative stresses. Appl Environ Microbiol 2011, 77:5604-5609.

75. Gury J, Barthelmebs L, Cavin JF: Random transposon mutagenesis of Lactobacillus plantarum by using the pGh9:IS S1 vector to clone genes involved in the regulation of phenolic acid metabolism. Arch Microbiol 2004, 182:337-345.

76. Elles LM, Uhlenbeck OC: Mutation of the arginine finger in the active site of Escherichia coli DbpA abolishes ATPase and helicase activity and confers a dominant slow growth phenotype. Nucleic Acids Res 2008, 36:41-50.

77. Roschanski N, Klages S, Reinhardt R, Linscheid M, Strauch E: Identification of genes essential for prey-independent growth of Bdellovibrio bacteriovorus HD100. J Bacteriol 2011, 193:1745-1756.

78. Mazzon RR, Lang EA, Braz VS, Marques MV: Characterization of Caulobacter crescentus response to low temperature and identification of genes involved in freezing resistance. FEMS Microbiol Lett 2008, 288:178-185.

79. Bergholz PW, Bakermans C, Tiedje JM: Psychrobacter arcticus 273-4 uses resource efficiency and molecular motion adaptations for subzero temperature growth. J Bacteriol 2009, 191:2340-2352.

80. Qiu X, Yan X, Liu M, Han R: Genetic and proteomic characterization of rpoB mutations and their effect on nematicidal activity in Photorhabdus luminescens LN2. PLoS One 2012, 7:e43114. 


\section{Figure 1}

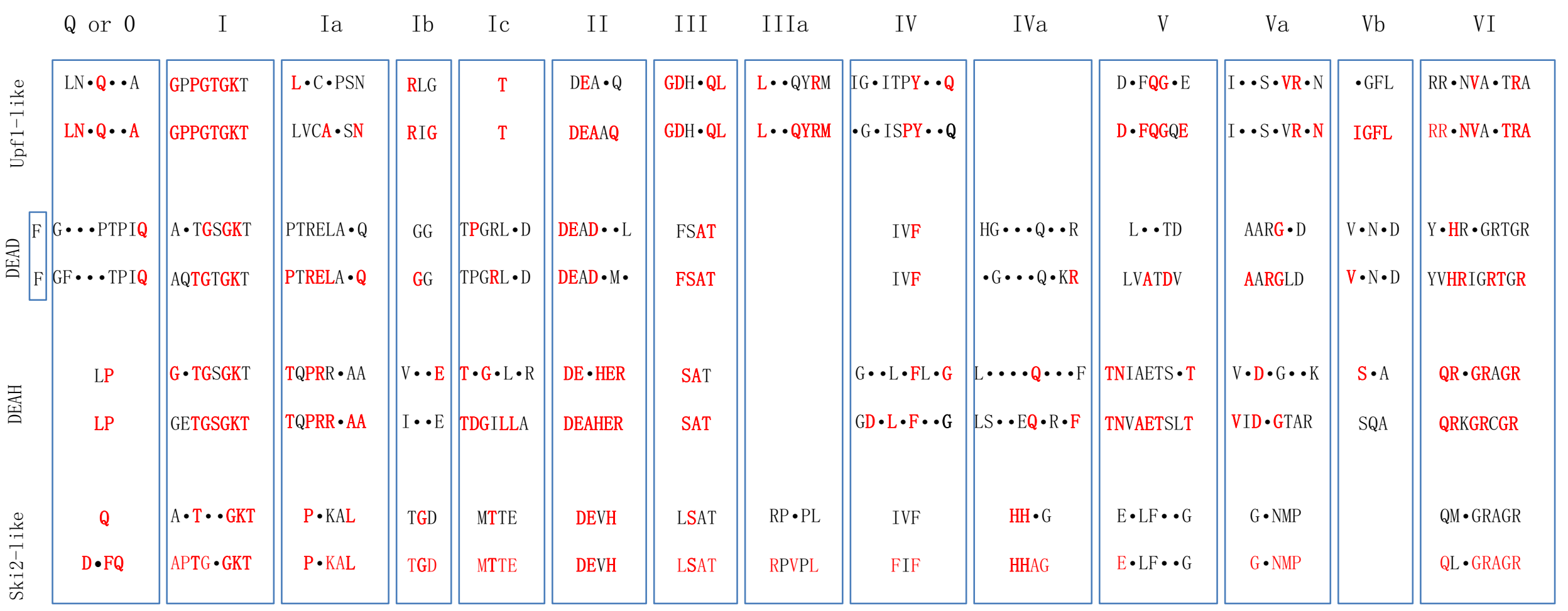


Figure 2a

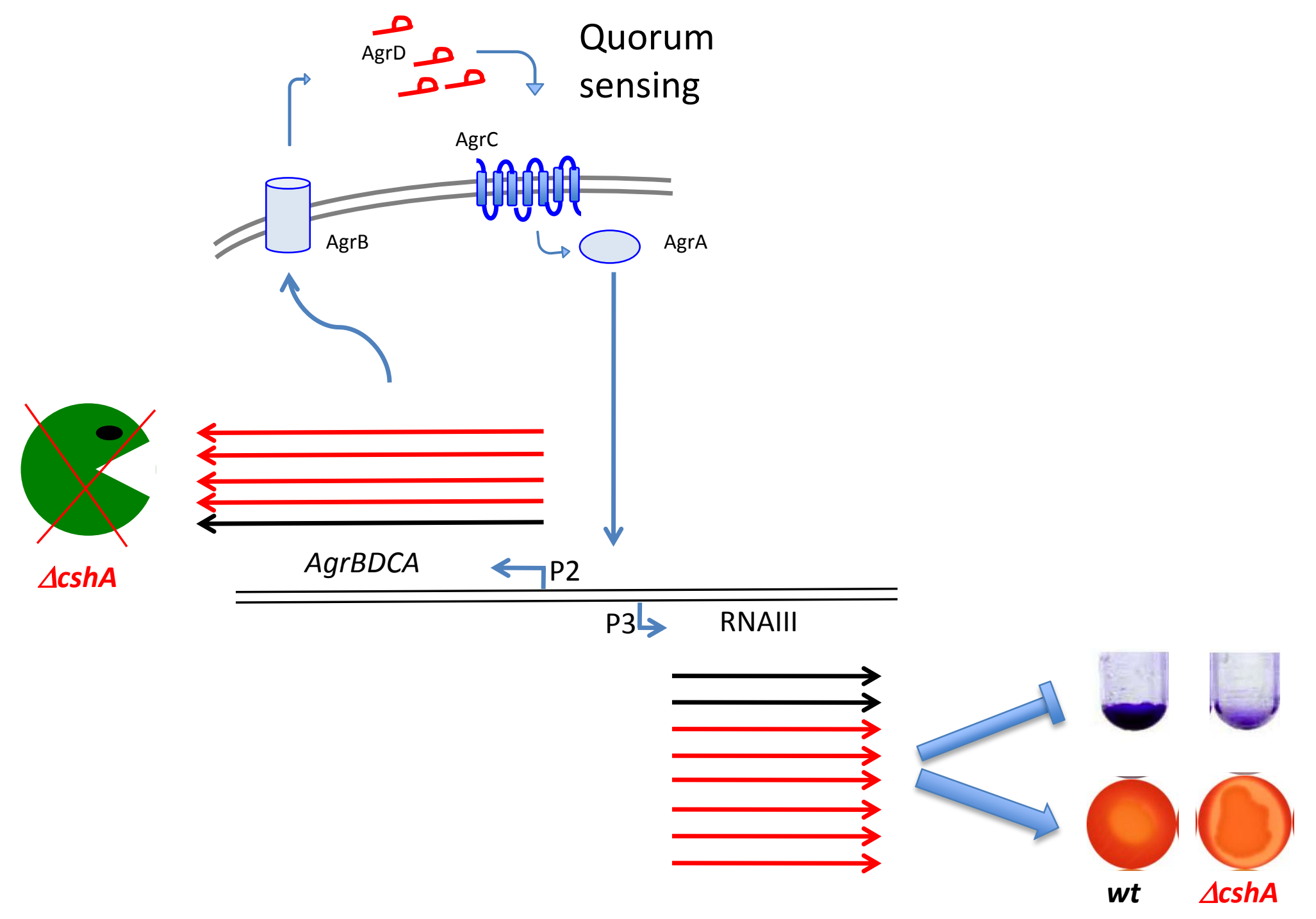




\section{Figure $2 b$}
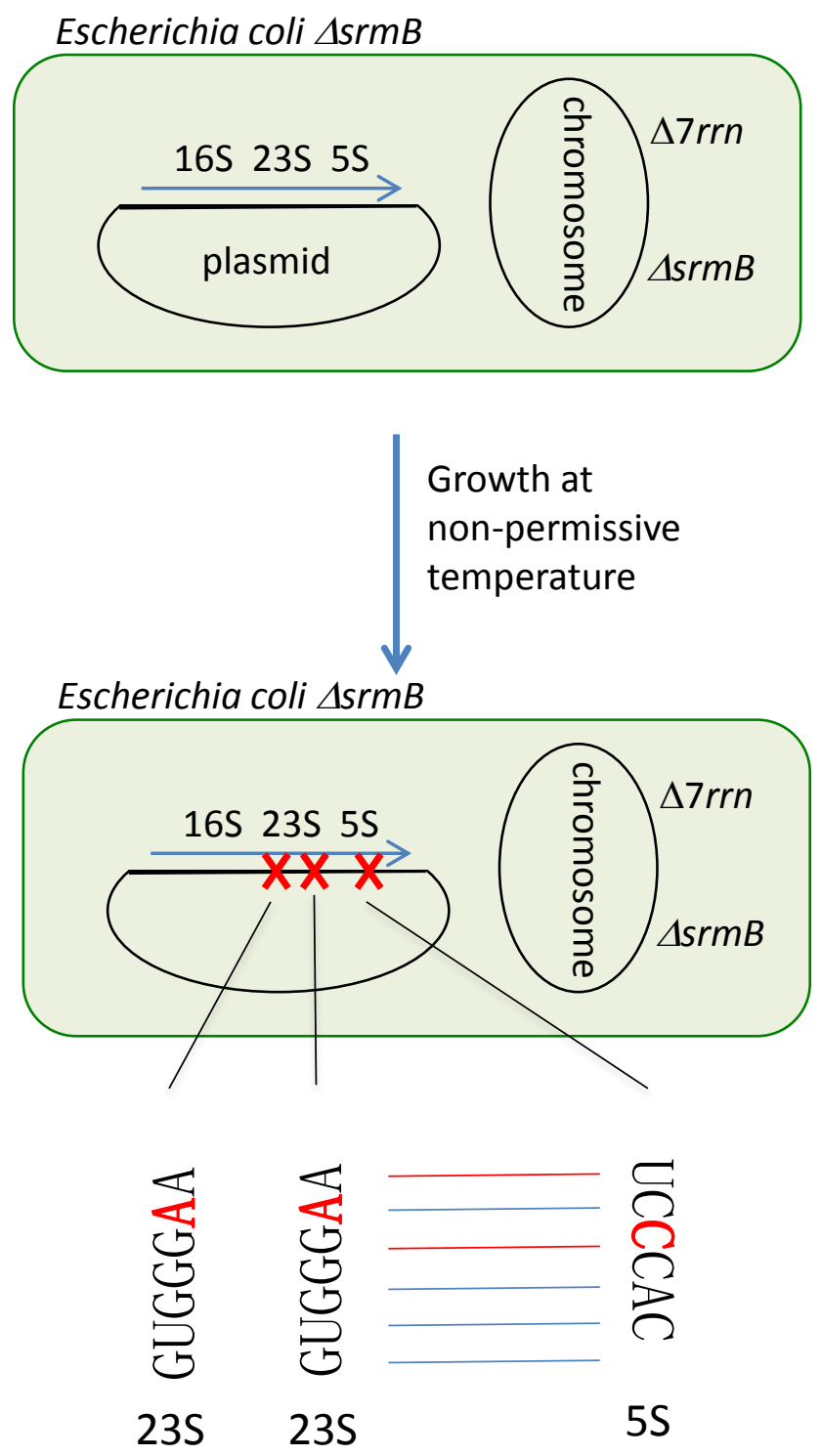
Figure 2c

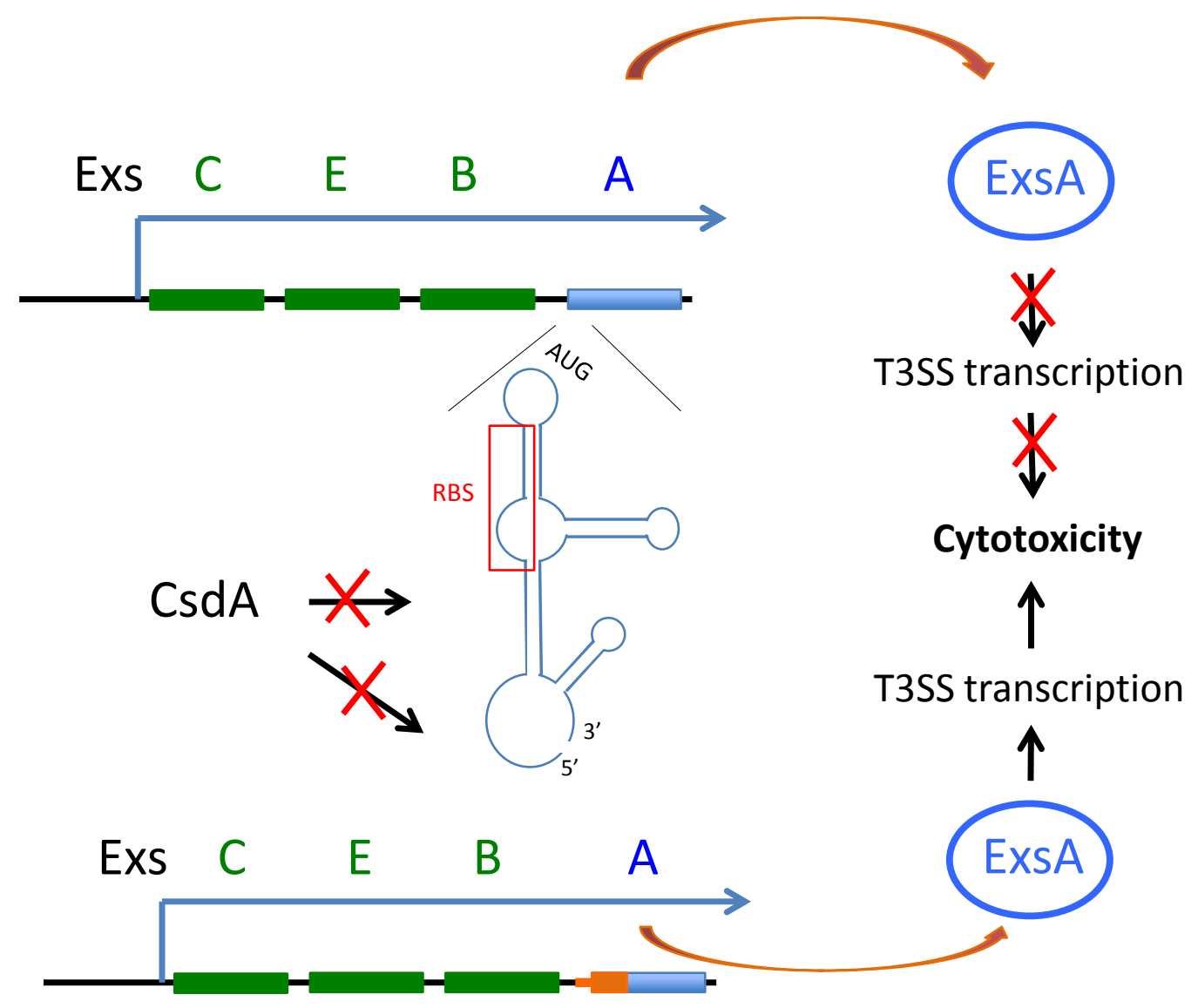

5'UTR replacement 
Figure 2d

Structural fimbrial protein

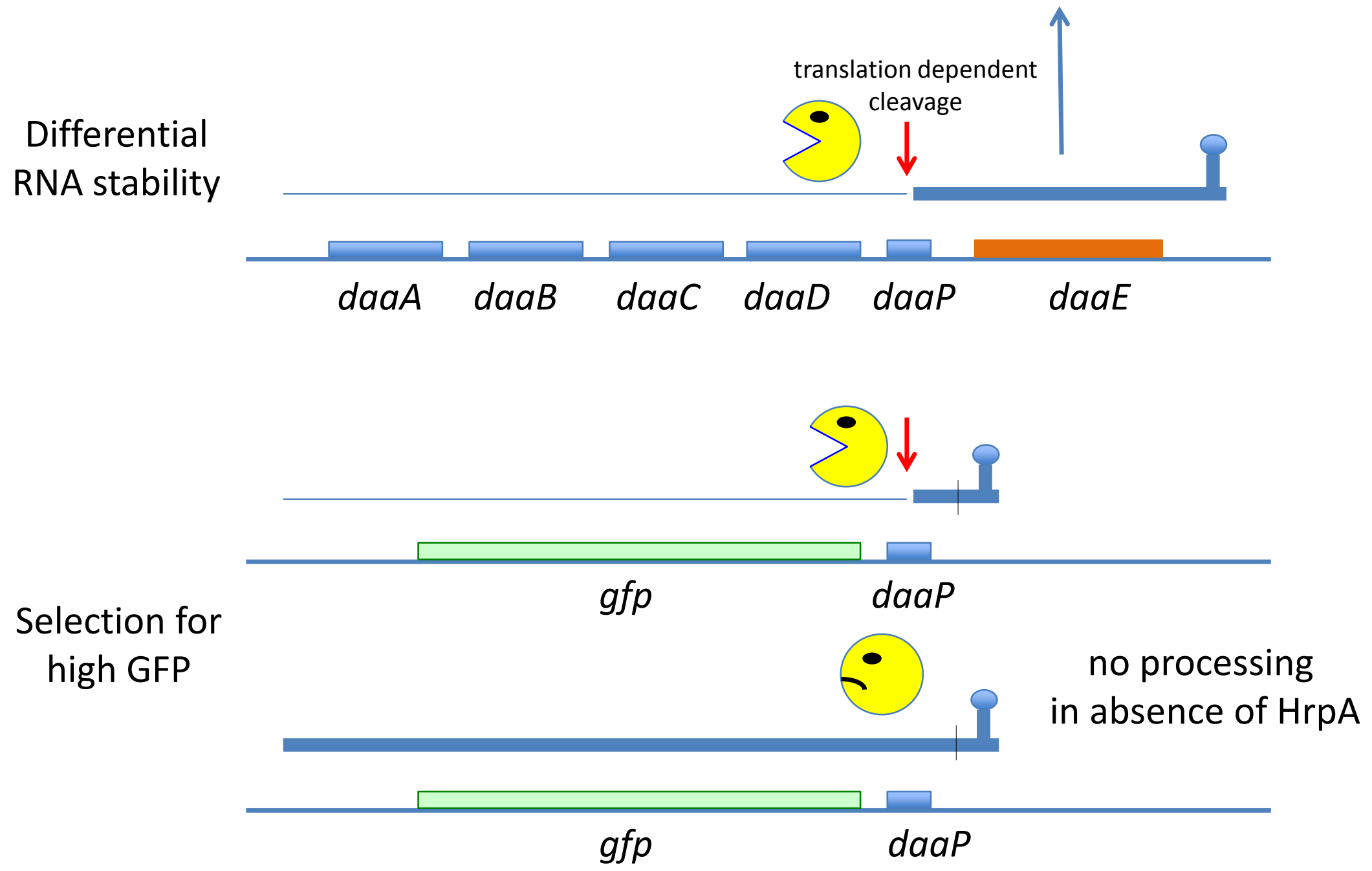




\section{RNA helicases}
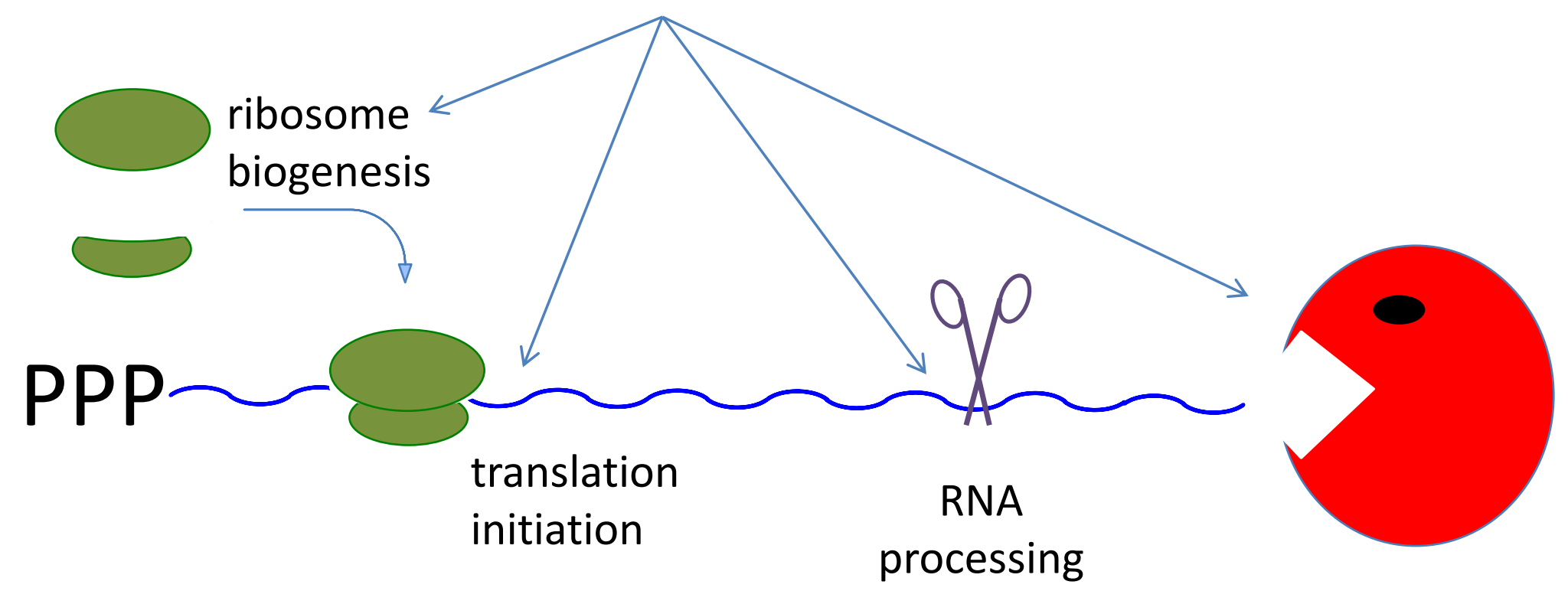

RNA decay 